\title{
Advances in molecular mechanisms of pelvic organ prolapse (Review)
}

\author{
ZHI-MIN DENG ${ }^{*}$, FANG-FANG DAI ${ }^{*}$, MENG-QIN YUAN, \\ DONG-YONG YANG, YA-JING ZHENG and YAN-XIANG CHENG \\ Department of Obstetrics and Gynecology, Renmin Hospital of \\ Wuhan University, Wuhan, Hubei 430060, P.R. China
}

Received March 30, 2021; Accepted June 18, 2021

DOI: $10.3892 /$ etm.2021.10442

\begin{abstract}
Pelvic organ prolapse (POP) is a common gynecological benign disease occurring in middle-aged and elderly females. Its incidence increases every year. To date, the majority of studies investigating its etiology have not evaluated the underlying molecular mechanisms, which has caused substantial difficulties in the prevention, treatment and prognosis of POP. In the present narrative review, recent research studies concerning the molecular mechanisms of POP were systematically reviewed and the advances were summarized. The association between the incidence of POP and the reduction of the extracellular matrix, activation of oxidative stress, genetic susceptibility, denervation of the pelvic floor and reduction of estrogen infiltration were explored. POP is mainly associated with damage of pelvic floor muscles and connective tissue, which are directly caused by pregnancy and vaginal delivery. The majority of the molecular and genetic mutations associated with POP involve specific components of connective tissue synthesis and degradation. It is likely that macroscopic parameters, such as anatomy, lifestyle and reproductive factors, interact with microscopic parameters, such as physiology and genetics in the female pelvic floor, leading to POP. Additional research studies investigating the molecular mechanisms of POP should be performed, since they may aid public health strategies. In the present narrative review, a summary of these molecular mechanisms underlying the development of POP is provided. This included the relevant proteins and genes involved. On this basis, countermeasures were proposed.
\end{abstract}

Correspondence to: Dr Yan-Xiang Cheng, Department of Obstetrics and Gynecology, Renmin Hospital of Wuhan University, 238 Jiefang Road, Wuchang, Wuhan, Hubei 430060, P.R. China E-mail:rm001050@whu.edu.cn

${ }^{*}$ Contributed equally

Key words: pelvic floor dysfunction, molecular mechanisms, extracellular matrix, genetic polymorphism

\section{Contents}

1. Introduction

2. Methods

3. Mechanisms underlying POP

4. OS and POP

5. Genetic susceptibility and POP

6. Reduction in the levels of neurotransmitters of the pelvic floor

7. Reduced content of estrogen

8. Discussion

\section{Introduction}

In a clinically-based consensus report, pelvic organ prolapse (POP) was defined as 'the downward descent of the anterior or posterior vaginal wall, the uterus and the vaginal vault into or through the vagina' (1). In total, 30-76\% of females present with POP during routine gynecological examinations, even in the absence of specific alarming symptoms (2). This condition may have a negative impact on sexual life, body image and quality of life (2). According to a study performed by Wu et al (3), the number of females with POP is expected to increase to $46 \%$ and is estimated to reach 4.9 million by 2050 . Aging increases the incidence of POP, which requires significant costs and causes a financial burden to the healthcare system.

POP is a multifactorial disease and pregnancy is the most common risk factor for its development. Labor directly damages the pelvic floor muscles and connective tissues (4). A prospective ultrasound study indicated that the incidence of pelvic floor muscle injury was associated with POP and its incidence ranged from 21-36\% following vaginal delivery (5). In addition, prior to hysterectomy, estrogen levels, parity, age, body mass index (BMI) and sustained elevated intra-abdominal pressure, including obesity, chronic cough, constipation and repeated weight-bearing, may also contribute to prolapse (6).

It is worth noting that the aforementioned macroscopic factors cannot fully clarify the pathogenesis of POP, which may not occur in all females exposed to these risk factors. Therefore, prolapse may also affect females who do not present with these conditions. Therefore, it is imperative to fully investigate the 
mechanisms of action of POP. The molecular mechanism of POP and the key genes involved in its development have been studied in-depth using bioinformatic approaches, such as genetic engineering and gene expression profiling chips. In the present review article, a summary of the latest advances of the molecular mechanisms of POP is provided, with a view to provide novel perspectives in elucidating the pathogenesis, identifying prevention methods and improving the means of diagnosis and treatment.

\section{Methods}

A comprehensive search of relevant systematic reviews and articles was performed using the PubMed and Google Scholar databases. This review adheres to Preferred Reporting Items for Systematic reviews and Meta-Analyses guidelines (7). The publication years ranged between 2005 and 2020. To expand the retrieval scope, the 'pelvic floor dysfunction' (PFD) concept was introduced. The search strategies included the following Mesh terms: 'Pelvic organ prolapse' and 'pelvic floor dysfunction'; 'PFD' and 'POP'; 'etiology' and 'mechanism'. Furthermore, citation tracking of the studies retrieved was used to identify additional relevant articles, which were obtained using Google Scholar. Table I illustrates the general idea of the study and the cited references, correspondingly.

\section{Mechanisms underlying POP}

The molecular mechanisms of POP are complex and have remained to be fully elucidated. They may be divided into the following aspects: i) Reduction of the extracellular matrix (ECM) in pelvic floor connective tissue; ii) activation of oxidative stress (OS); iii) genetic susceptibility; iv) denervation of the pelvic floor; and v) reduction of estrogen infiltration (Fig. 1).

Reduced ECM and POP. The connective tissue of the pelvic floor is composed of nerves, muscles, ligaments and fascia, and supports the female pelvic organs. The fibroblasts secrete collagen and elastin, which are the essential components of the ECM that provide strength and flexibility to the pelvic floor (8). To the best of our knowledge, reduced ECM metabolism in pelvic floor connective tissue, including reduced anabolism and increased catabolism, is the predominant pathogenic mechanism of POP.

Reduced anabolism of ECM. The research hotspot in the field of collagen synthesis is transforming growth factor- $\beta 1$ (TGF- $\beta 1$ ), a typical multifunctional cytokine, which broadly regulates various biological functions and has been indicated to be involved in the synthesis of connective tissue (9). It has been confirmed that decreased mRNA and protein expression levels of TGF- $\beta 1$ are associated with the severity of POP (10). Pretreatment with TGF- $\beta 1$ activates the TGF- $\beta 1 / \mathrm{Smad}$ signaling pathway, thereby attenuating the loss of ECM (11). Investigation of its mechanistic involvement in chronic kidney diseases and idiopathic pulmonary fibrosis has resulted in the conclusion that TGF- $\beta 1$ promotes collagen synthesis via the following methods: i) Activation of downstream signaling pathways, such as the TGF- $\beta 1 /$ Smad pathway; ii) increased de novo synthesis of serine; and iii) increased expression of protease inhibitors $(12,13)$. It is reasonable to hypothesize that downregulation of TGF- $\beta 1$ hinders collagen synthesis, interferes with ECM metabolism and ultimately affects the occurrence and development of POP.

In addition, a previous study published in 2008 reported that the homeobox A11 (HOXA11) gene, which is a transcriptional regulator, is key to the balance of collagen metabolism and its deficiency was associated with a decrease in collagen content (14). Another study had indicated that HOXA11 inhibits the expression of $\mathrm{p} 53$, a tumor suppressor gene, which controls the progression of the cell cycle (15). This may be a mechanism via which HOXA11 regulates collagen synthesis. In addition, it has been demonstrated that the expression levels of matrix metalloproteinase (MMP) enzymes are increased, while those of tissue inhibitors of MMP (TIMPs) are decreased following knockdown of HOXA11 expression, which in turn increases the degradation of ECM, suggesting that a deficiency in HOXA11 disrupts the balance of collagen metabolism and eventually contributes to POP (16). A study indicated that the expression levels of microRNA (miRNA/miR)-30D and miR-181A in patients with POP were negatively correlated with HOXA11 mRNA levels; it was hypothesized that these miRNAs regulate the expression of HOXA11 and may be used as therapeutic targets for POP (17).

The above findings suggest that HOXA11 and TGF- $\beta 1$ exert a synergistic effect on the expression of collagen and MMP enzymes. These two signaling mediators have important roles in the development of ECM, as demonstrated by a recent study (18). The balanced turnover of collagen is necessary for maintaining the mechanical strength of pelvic supportive connective tissues.

The major components of ECM are elastic fibers and collagen. Elastic fibers are able to maintain the integrity of pelvic organs and vaginal structures to resist mechanical strain due to its elasticity and recoil properties (18). Patients with POP exhibit weakened flexibility of elastin and increased flexibility of elastase, which disrupts the mechanical balance of the pelvic floor (19). Fibulin-5 (FBLN5) and lysyl oxidase-like protein 1 (LOXL1) have attracted considerable attention due to their major roles in the synthesis of elastic fibers (20-25).

FBLN5 is an integrin-bound matricellular protein required for elastic fiber assembly; it exerts dual effects by ensuring normal assembly of elastic fibers and inhibiting the activity of MMP9 to maintain the biomechanical integrity of the pelvic floor and prevent the development of POP (20). An additional study indicated that FBLN5 inhibits upregulation of MMP9 by inhibiting $\beta 1$ integrin-dependent and fibronectin-mediated pathways (21).

LOXL1 is involved in the cross-linking of tropoelastin monomers and interacts with FBLN5 (22). It serves both as a cross-linking enzyme and as an element of the scaffold, having an essential role in the synthesis and assembly of elastic fibers (23). Previous studies have clarified that defect in the synthesis of elastic fibers caused by decreased expression of FBLN5 and LOXL1 contribute to POP $(24,25)$. It was recently determined that the coexpression of LOXL1 and bone morphogenetic protein has a significant impact on the regulation of postpartum connective tissue metabolism in mice (22).

In summary, the disordered elastic fiber homeostasis may weaken the function of the stent, which is one of the primary events in the pathogenesis of POP. 
Table I. Molecular mechanisms of pelvic organ prolapse.

\begin{tabular}{|c|c|c|}
\hline Category & Factors & (Refs.) \\
\hline \multicolumn{3}{|l|}{ Reduction of ECM } \\
\hline \multirow[t]{4}{*}{ Reduced anabolism } & TGF- $\beta 1$ & $(9-13,18)$ \\
\hline & HOXA11 & $(14-18)$ \\
\hline & FBLN5 & $(20,21)$ \\
\hline & LOXL1 & $(22-25,68)$ \\
\hline Increased catabolism & MMPs/TIMPs, elastases & $(10,11,16,18,20,27-30)$ \\
\hline Activation of oxidative stress & $\mathrm{NA}^{\mathrm{a}}$ & $(32-38)$ \\
\hline Genetic susceptibility & NA & Table II ${ }^{\mathrm{b}}$ \\
\hline \multirow[t]{2}{*}{ Reduction of neurotransmitters } & VIP & $(63,64)$ \\
\hline & NPY & $(63,64,68)$ \\
\hline Reduction of estrogen infiltration & NA & $(65-67)$ \\
\hline
\end{tabular}

${ }^{\mathrm{a}}$ For rows containing NA, there is no precise factor available for that molecular mechanism; ${ }^{\mathrm{b}}$ Details are presented in Table II. ECM, extracellular matrix; TGF- $\beta 1$, transforming growth factor- $\beta 1$; HOXA11, homeobox A11; FBLN5, fibulin-5; LOXL1, lysyl oxidases-like protein 1; MMPs, matrix metalloproteinases; TIMPs, tissue inhibitors of MMP; NPY, neuropeptide; VIP, vasoactive intestinal peptide.
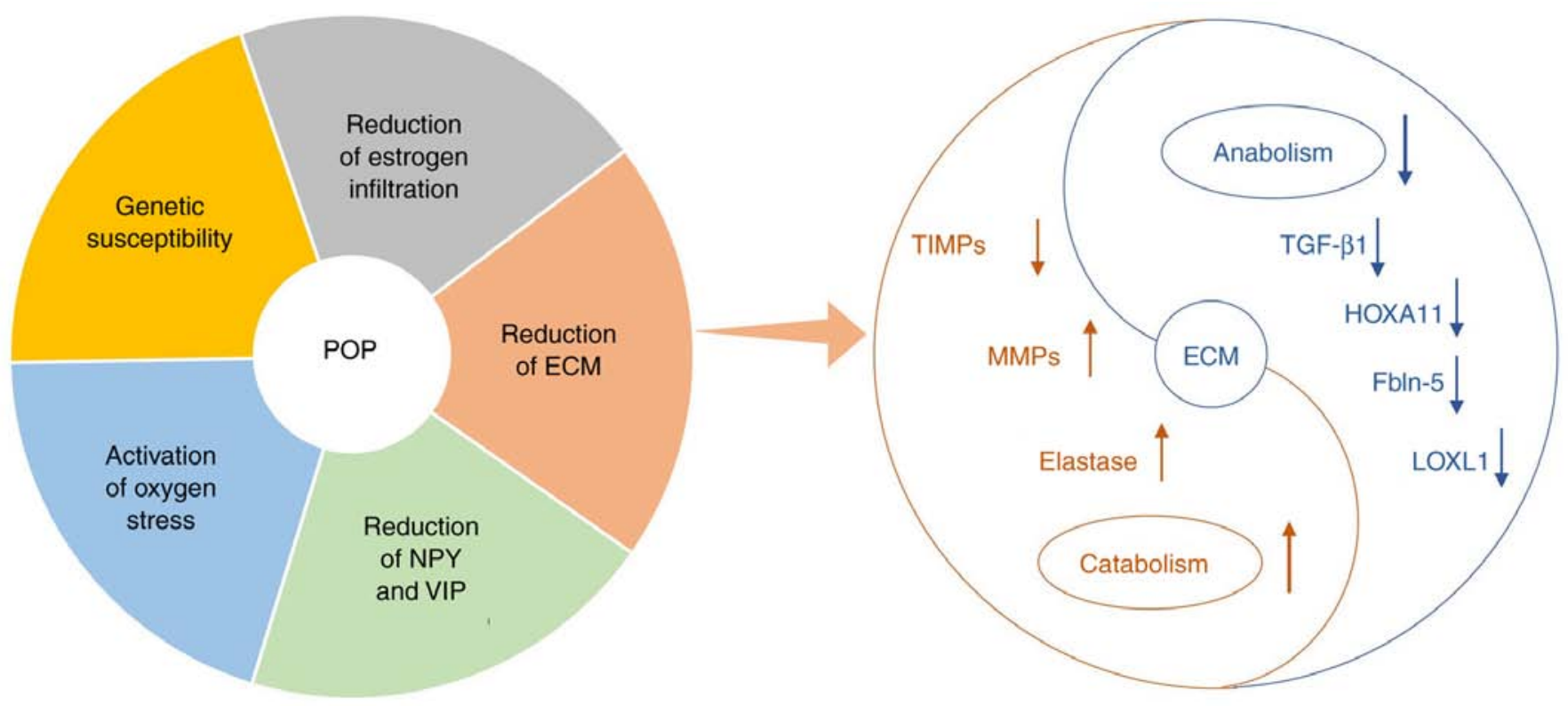

Figure 1. Overview diagram of the article. (A) Pie chart of the five core factors of POP. (B) Specific molecular mechanisms involved in the reduction of ECM. POP, pelvic organ prolapse; ECM, extracellular matrix; TGF- $\beta 1$, transforming growth factor- $\beta 1$; HOXA11, homeobox A11; FBLN5, fibulin-5; LOXL1, lysyl oxidases-like protein 1; MMPs, matrix metalloproteinases; TIMPs, tissue inhibitors of MMP; NPY, neuropeptide; VIP, vasoactive intestinal peptide.

Increased catabolism of ECM. MMPs mainly include MMP1, -2, -3 and -9. These enzymes are capable of degrading collagen and other ECM components (26). A previous study indicated that overexpression of MMP2 is a harmful factor for POP (27). In patients with POP, the expression levels of MMP2/9 in the pelvic floor tissue were increased, while those of TIMPs, which antagonize MMP action, were decreased (16). Therefore, MMPs and TIMPs are considered the key factors of regulating ECM degradation. In addition, it has been reported that TGF- $\beta 1$ stimulates the synthesis of TIMP-2 and inhibits the activity of MMP2/9 via the TGF- $\beta 1 / \mathrm{Smad} 3$ signaling pathway, thereby reducing the loss of ECM $(10,11)$. However, an additional study that utilized a rainbow trout heart fibrosis model indicated that following $24 \mathrm{~h}$ of TGF- $\beta 1$ treatment, the transcription levels of TIMP-2 and MMP9 were increased (28). Heterogeneity among studies, such as differences in research methods, sample sizes, research subjects, locations of biopsy materials and genetic background, may lead to such distinct outcomes.

A previous study compared the expression levels of various elastases in vaginal tissues of female patients with pelvic floor dysfunction and confirmed that increased elastin metabolism may alter the mechanical properties of supporting tissues (29). A subsequent study indicated that increased expression of 
elastase causes rupture of elastic fibers, leading to the destruction of the structural integrity of the pelvic floor and increased risk of prolapse (30).

In summary, MMP and TIMP functions are balanced in order to regulate ECM anabolism. HOXA11, TGF- $\beta 1$ and FBLN5 influence the expression of MMPs $(16,18,20)$. It may be considered that the anabolism and catabolism of ECM are inseparable and intricate. Decreased anabolism and increased catabolism are key factors for the onset of POP.

\section{OS and POP}

OS may cause increased oxidative modification of DNA, lipids and proteins, and induce mitochondrial apoptosis (31). Its role in the pathogenesis of POP has received increased attention. OS is indicated to be able to interfere with key points of elastic fiber assembly and reduce the quality of elastin (32). A previous study published in 2013 indicated that the balance of oxidation and antioxidation in females with POP was disrupted, which increased the levels of reactive oxygen species (ROS) and downregulated the TGF- $\beta 1$ signaling pathway. This caused inhibition of collagen synthesis and damage to the pelvic support structure (33). In addition, it has been reported that the levels of 8-hydroxy-2-deoxyguanosine and 4-hydroxynonenal, which are biomarkers of oxidative damage and may be used to determine OS and mitochondrial apoptosis, are involved in the pathological process of POP (34). Another study determined that the levels of ROS and the apoptotic rate of fibroblasts were enhanced following an increase in mechanical stress, which indicates that mechanical strain promotes the development of POP by activating ROS (35). A further study concluded that mechanical strain may activate the PI3K/AKT-mediated OS signaling pathway, thereby promoting the apoptosis and senescence of pelvic fibroblasts, and reducing the production of collagen (36). A subsequent study also confirmed this notion (37). Furthermore, reduced OS has been indicated to promote collagen synthesis, while its overexpression may interfere with the homeostasis and metabolism of ECM by affecting the levels of MMPs/TIMPs and the activation of the TGF- $\beta 1 / \mathrm{Smad}$ signaling pathway, which in turn results in induction of POP (38).

Based on these results, it is hypothesized OS hinders the balance of MMPs/TIMPs and interferes with the TGF- $\beta 1 / \mathrm{Smad}$ pathway, which negatively affects the production of elastic fibers, thereby destroying the pelvic floor support network and ultimately leading to the occurrence of POP.

\section{Genetic susceptibility and POP}

It is becoming increasingly accepted that fertility-associated factors are the most common pathogenic driving factors of POP. However, this cannot fully explain the development of POP in nulliparous females without any known risk factors. In addition, the notable medical history of POP is not only based on the obstetric and gynecological history, but also on the family history. In the case of a positive family history, the risk of POP is increased. Table II displays the evidence that indicates that genetic factors may be involved in the development of POP. The majority of the gene mutations currently known to be associated with POP are located in the coding regions of the genes
Table II. Susceptibility genes of POP.

\begin{tabular}{lcc}
\hline Genetic entity & $\begin{array}{c}\text { Proven susceptibility } \\
\text { yes/no }\end{array}$ & $($ Refs. $)$ \\
\hline COL3A1 rs1800255 & Yes & $(39,40,42,45)$ \\
& No & $(41,43,44,46)$ \\
COL1A1 rs1800012 & Yes & $(46)$ \\
& No & $(49,51)$ \\
LAMC1 rs10911193 & No & $(46,48,52)$ \\
ESR1 rs2228480 & Yes & $(47,48)$ \\
& No & $(49)$ \\
PGR rs484389 & Yes & $(53)$ \\
MMP1 & Yes & $(51)$ \\
& No & $(46)$ \\
HOXA11 & No & $(49)$ \\
LOXL1 & Yes & $(54)$ \\
FBLN5 & Yes & $(55)$ \\
& No & $(56)$ \\
Chromosomes & Yes & $(57-59)$ \\
9q21/10q24-26/17q25 & & \\
\end{tabular}

${ }^{a}$ Yes/no refers to whether this gene has been proven to be a susceptibility gene for POP; 'Yes' means that it is a susceptibility gene for POP, while 'no' means that there is insufficient evidence to prove that it is a susceptibility gene for POP. POP, pelvic organ prolapse; COL1A1, collagen type I $\alpha 1$; COL3A1, collagen type III $\alpha$ 1; ESR1, estrogen receptor $\alpha$; FBLN5, fibulin-5; LAMC1, laminin $\gamma$-1; MMP1, matrix metalloproteinases 1; PGR, progesterone receptor; LOXL1, lysyl oxidases-like protein 1; HOXA11, homeobox A11.

encoding for the aforementioned proteins, such as TGF- $\beta 1$, FBLN5 and LOXL1. These mutations may lead to changes in the functions of those molecules and to the development of POP with the combined action of environmental factors.

The genetic polymorphism of the collagen type III $\alpha 1$ (COL3A1) gene leads to amino acid changes in the cy1 (III) chain, which may interfere with the mechanical properties of type III collagen and affect the supporting structure of the pelvic floor. The single nucleotide polymorphism (SNP) G/A rs1800255 is located in the coding region of COL3A1 and has been evaluated as a possible risk factor for POP (39-45). The conclusions of research on this aspect are conflicting. A systematic review has summarized pedigree studies on POP published in 2005-2013 and concluded that only the presence of the rs1800012 polymorphism of COL1A1 was associated with the incidence of POP, while the rs 1800255 polymorphism of COL3A1 did not exhibit any significant association with the development of this disease (46). However, a previous study published in 2014 performed a genetic epidemiological assessment on POP and demonstrated that the probability of developing the disease increased to 4.79 -fold in the presence of the COL3A1 rs1800255 genotype (45). This study further demonstrated that the polymorphic site rs2228480 of the estrogen receptor $\alpha$, which is encoded by estrogen receptor 1 (ESR1), was a susceptibility factor for the development of POP, which was subsequently confirmed by additional studies $(47,48)$, although conflicting results have also been 
reported (49). A previous study indicated that miR-221 and miR-222, two regulatory factors of ESR1, negatively regulate the expression of ESR1 in patients with POP (50). The aforementioned results demonstrated that the ESR1 genotype may be a predisposing factor for POP and that it may be used as a potential therapeutic target for this disease. Apart from the aforementioned genes (COL3A1 rs1800255; COL1A1 rs1800012; ESR1 rs2228480), other genes involved in the occurrence and development of POP have been discovered, including MMP1, laminin $\gamma-1$ rs10911193, progesterone receptor rs484389, LOXL1 and common SNPs of the FBLN5 gene (rs2018736, rs12589592) (48,51-56). In addition, genome-wide association studies have determined that the presence of chromosomes $9 q 21,10 q 24-26$ and $17 q 25$ is associated with the susceptibility of European patients with POP (57-59). However, the susceptibility loci on these chromosomes remain to be identified (60).

From aforementioned research, it is important to note that several research results are contradictory, as indicated in Table II. As stated by Cartwright 'many studies were at high risk of bias from genotyping error or population stratification' (46), which may contribute the contradictory results. In addition, the heterogeneity among studies in terms of differences in the genetic background of participants and gene sequencing methods may also led to inconsistent results. The rapid development of gene expression analysis and high-throughput sequencing technology has enabled the successful identification of genes and pathways that may provide detailed information on the molecular mechanisms underlying POP $(61,62)$. These genes may be used as potential biomarkers of POP.

\section{Reduction in the levels of neurotransmitters of the pelvic floor}

It is well accepted that vaginal delivery and multiple pregnancies lead to overstretching of the pelvic floor nerves and muscles. During this process, the nerves suffer more damage due to their weaker ability to withstand traction compared with that of the muscles (63). Abnormalities in peptide neurotransmitters, notably vasoactive intestinal peptide (VIP) and neuropeptide (NPY), reflect the degree of denervation of the pelvic floor structure, promote pelvic and vaginal blood flow and serve as a critical marker for evaluating pelvic floor nerve injury (64). Accumulating evidence has demonstrated that the expression levels of VIP and NPY in patients with POP are decreased $(63,64)$. Their absence results in changes in blood flow, muscle atrophy, local nutritional insufficiency and ultimately dysfunction in the pelvic floor of females. Furthermore, the decreased expression levels are associated with the severity of the symptoms $(63,64)$. To date, only a small number of studies have been performed to assess the levels of neuropeptides in the pelvic floor, and the scope to explore the underlying mechanisms of chemical transmitter loss following nerve damage remains limited.

\section{Reduced content of estrogen}

It has been indicated that increased risk of pelvic floor disease following menopause may be associated with estrogen deficiency, whereas changes in the expression of estrogen receptors also affect the risk to females of developing POP (65). A previous study demonstrated that estrogen may increase collagen turnover and positively affect pelvic floor tissue (66). Furthermore, estrogen has been indicated to stimulate and increase collagen content, thereby enhancing the resistance of the pelvic floor network structure (67). It is now widely accepted that following menopause, the secretion of estrogen in females decreases rapidly and the connective tissue cannot be repaired effectively, which weakens the function of the supporting network. Furthermore, it has been indicated that estrogen affects the content of LOXL1 and the distribution of NPY (68).

Consequently, exogenous estrogen has long been suggested for the treatment or prevention of POP. It is able to improve the homeostasis of the pelvic floor; however, it has been noted to have certain side effects, such as dizziness, endometrial disease, uterine fibroids and endocrine disorders (69). Although its therapeutic effects have been reported, there is still insufficient evidence to prove its effectiveness. According to a 2017 retrospective observational study, the use of exogenous estrogen and its substitutes has limited benefits for genitourinary syndrome in menopausal females (70). Therefore, the effectiveness and safety of this treatment should be reviewed comprehensively and systematically.

\section{Discussion}

Although POP is not life-threatening, it may be painful, embarrassing and uncomfortable. Its incidence and prevalence increase with age. The risk factors for POP are considered to include age, parity, vaginal delivery, obesity, diabetes, previous hysterectomy and connective tissue diseases. To prevent POP, the BMI is the only risk factor that may be controlled. Generally speaking, parity and delivery methods may be changed, whereas in practice, POP is rarely taken into consideration. Therefore, it is crucial to further explore its underlying molecular mechanisms, unravel the complex causal network composed of factors such as heredity, reproductive factors and lifestyle, and seek improved prevention and treatment targets. Since the technology on bioinformatics and gene microarray had made great progress in in recent years, the revision and supplementation of previous data is required.

The present review summarized the molecular mechanisms of POP into five aspects, including the metabolism of ECM, OS activation, genetic susceptibility, pelvic floor denervation and reduction of estrogen infiltration. In addition, the following strategies are proposed with regard to prevention: i) High-risk groups should attempt to avoid pathological conditions with increased abdominal pressure, such as chronic cough; and ii) females with a family history should undergo genetic testing and POP screening as soon as possible. Furthermore, the following strategies were adopted with regard to treatment: i) Although the use of estrogen following menopause may be promising, further investigation is required to confirm its efficacy; ii) the choice of treatment method (conservative or surgery) should rely on the collaboration between specialized teams and shared decision-making with patients; and iii) in addition to improving the symptoms of the patients, attention should be paid to their quality of life and mental health. Investing additional manpower and resources to systematically evaluate the mechanisms of POP is beneficial to both prevention and treatment. Comprehensive utilization of 
multidisciplinary approaches may provide breakthroughs and novel ideas for studying the pathogenesis of POP.

\section{Acknowledgements}

Not applicable.

\section{Funding}

This work was supported by the Key Research and Development Program of Hubei Province (grant no. 2020BCB023), the China Graduate School of Graduate Education Fund Project (grant no. B2-YX20180302-19), the Renmin Hospital of Wuhan University Guidance Fund Project (grant no. RMYD2018M05) and the Education and Teaching Reform Research Project of Wuhan University (grant no. 413200095).

\section{Availability of data and materials}

Not applicable.

\section{Authors' contributions}

ZMD conceived and designed the study. FFD, MQY, DYY and YJZ performed the literature search. ZMD drafted the manuscript and prepared the tables. YXC revised the manuscript and acquired funding. All authors read and approved the final manuscript. Data authentication is not applicable.

\section{Ethics approval and consent to participate}

Not applicable.

\section{Patient consent for publication}

Not applicable.

\section{Competing interests}

The authors declare that they have no competing interests.

\section{References}

1. Haylen BT, Maher CF, Barber MD, Camargo S, Dandolu V, Digesu A, Goldman HB, Huser M, Milani AL, Moran PA, et al: An International Urogynecological Association (IUGA) International Continence Society (ICS) joint report on the terminology for female pelvic organ prolapse (POP). Int Urogynecol J Pelvic Floor Dysfunct 27: 165-194, 2016.

2. Barber MD: Pelvic organ prolapse. BMJ 354: i3853, 2016.

3. Wu JM, Hundley AF, Fulton RG and Myers ER: Forecasting the prevalence of pelvic floor disorders in U.S. Women: 2010 to 2050. Obstet Gynecol 114: 1278-1283, 2009.

4. Iglesia CB and Smithling KR: Pelvic Organ Prolapse. Am Fam Physician 96: 179-185, 2017.

5. van Delft K, Sultan AH, Thakar R, Schwertner-Tiepelmann N and Kluivers K: The relationship between postpartum levator ani muscle avulsion and signs and symptoms of pelvic floor dysfunction. BJOG 121: 1164-1172, 2014.

6. Friedman T, Eslick GD and Dietz HP: Risk factors for prolapse recurrence: Systematic review and meta-analysis. Int Urogynecol J Pelvic Floor Dysfunct 29: 13-21, 2018.

7. Moher D, Liberati A, Tetzlaff J and Altman DG; PRISMA Group: Preferred reporting items for systematic reviews and meta-analyses: the PRISMA statement. BMJ 339:b2535, 2009.
8. Chen B and Yeh J: Alterations in connective tissue metabolism in stress incontinence and prolapse. J Urol 186: 1768-1772, 2011.

9. Yang L, Pang Y and Moses HL: TGF-beta and immune cells: An important regulatory axis in the tumor microenvironment and progression. Trends Immunol 31: 220-227, 2010.

10. Liu C, Wang Y, Li BS, Yang Q, Tang JM, Min J, Hong SS, Guo WJ and Hong L: Role of transforming growth factor $\beta 1$ in the pathogenesis of pelvic organ prolapse: A potential therapeutic target. Int J Mol Med 40: 347-356, 2017.

11. Min J, Li B, Liu C, Guo W, Hong S, Tang J and Hong L: Extracellular matrix metabolism disorder induced by mechanical strain on human parametrial ligament fibroblasts. Mol Med Rep 15: 3278-3284, 2017.

12. Meng XM, Nikolic-Paterson DJ and Lan HY: TGF- $\beta$ : The master regulator of fibrosis. Nat Rev Nephrol 12: 325-338, 2016.

13. Nigdelioglu R, Hamanaka RB, Meliton AY, O'Leary E, Witt LJ, Cho T, Sun K, Bonham C, Wu D, Woods PS, et al: Transforming Growth Factor (TGF)- $\beta$ Promotes De Novo Serine Synthesis for Collagen Production. J Biol Chem 291: 27239-27251, 2016.

14. Connell KA, Guess MK, Chen H, Andikyan V, Bercik R and Taylor HS: HOXA11 is critical for development and maintenance of uterosacral ligaments and deficient in pelvic prolapse. J Clin Invest 118: 1050-1055, 2008.

15. Connell KA, Guess MK, Chen HW, Lynch T, Bercik R and Taylor HS: HOXA11 promotes fibroblast proliferation and regulates p53 in uterosacral ligaments. Reprod Sci 16: 694-700, 2009.

16. Ma Y, Guess M, Datar A, Hennessey A, Cardenas I, Johnson J and Connell KA: Knockdown of Hoxa11 in vivo in the uterosacral ligament and uterus of mice results in altered collagen and matrix metalloproteinase activity. Biol Reprod 86: 100, 2012.

17. Jeon MJ, Kim EJ, Lee M, Kim H, Choi JR, Chae HD, Moon YJ, Kim SK and Bai SW: MicroRNA-30d and microRNA-181a regulate HOXA11 expression in the uterosacral ligaments and are overexpressed in pelvic organ prolapse. J Cell Mol Med 19: 501-509, 2015.

18. Zhang L, Dai F, Chen G, Wang Y, Liu S, Zhang L, Xian S, Yuan M, Yang D, Zheng Y, et al: Molecular mechanism of extracellular matrix disorder in pelvic organ prolapses. Mol Med Rep 22: 4611-4618, 2020.

19. Chin K, Wieslander C, Shi H, Balgobin S, Montoya TI, Yanagisawa H and Word RA: Pelvic Organ Support in Animals with Partial Loss of Fibulin-5 in the Vaginal Wall. PLoS One 11: e0152793, 2016.

20. Northington GM: Fibulin-5: Two for the price of one maintaining pelvic support. J Clin Invest 121: 1688-1691, 2011.

21. Budatha M, Roshanravan S, Zheng Q, Weislander C, Chapman SL, Davis EC, Starcher B, Word RA and Yanagisawa H: Extracellular matrix proteases contribute to progression of pelvic organ prolapse in mice and humans. J Clin Invest 121: 2048-2059, 2011.

22. Borazjani A, Couri BM, Kuang M, Balog BM and Damaser MS: Role of lysyl oxidase like 1 in regulation of postpartum connective tissue metabolism in the mouse vagina. Biol Reprod 101: 916-927, 2019.

23. Liu X, Zhao Y, Gao J, Pawlyk B, Starcher B, Spencer JA, Yanagisawa $\mathrm{H}$, Zuo J and $\mathrm{Li}$ T: Elastic fiber homeostasis requires lysyl oxidase-like 1 protein. Nat Genet 36: 178-182, 2004.

24. Zhao BH and Zhou JH: Decreased expression of elastin, fibulin-5 and lysyl oxidase-like 1 in the uterosacral ligaments of postmenopausal women with pelvic organ prolapse. J Obstet Gynaecol Res 38: 925-931, 2012.

25. Kufaishi H, Alarab M, Drutz H, Lye S and Shynlova O: Comparative Characterization of Vaginal Cells Derived From Premenopausal Women With and Without Severe Pelvic Organ Prolapse. Reprod Sci 23: 931-943, 2016.

26. Cui N, Hu M and Khalil RA: Biochemical and Biological Attributes of Matrix Metalloproteinases. Prog Mol Biol Transl Sci 147: 1-73, 2017.

27. Phillips $\mathrm{CH}$, Anthony $\mathrm{F}$, Benyon $\mathrm{C}$ and Monga $\mathrm{AK}$ : Collagen metabolism in the uterosacral ligaments and vaginal skin of women with uterine prolapse. BJOG 113: 39-46, 2006.

28. Johnston EF and Gillis TE: Transforming growth factor beta-1 (TGF- $\beta 1$ ) stimulates collagen synthesis in cultured rainbow trout cardiac fibroblasts. J Exp Biol 220: 2645-2653, 2017.

29. Chen B, Wen Y and Polan ML: Elastolytic activity in women with stress urinary incontinence and pelvic organ prolapse. Neurourol Urodyn 23: 119-126, 2004.

30. Akintunde A, Robison KM, Capone D, Desrosiers L, Knoepp LR and Miller KS: Effects of elastase digestion on the murine vaginal wall biaxial mechanical response. J Biomech Eng 141: 0210111-02101111, 2018. 
31. Sosa V, Moliné T, Somoza R, Paciucci R, Kondoh H and LLeonart ME: Oxidative stress and cancer: an overview. Ageing Res Rev 12: 376-990, 2013.

32. Akhtar K, Broekelmann TJ, Miao M, Keeley FW, Starcher BC, Pierce RA, Mecham RP and Adair-Kirk TL: Oxidative and nitrosative modifications of tropoelastin prevent elastic fiber assembly in vitro. J Biol Chem 285: 37396-37404, 2010.

33. Li BS, Hong L, Min J, Wu DB, Hu M and Guo WJ: The expression of glutathione peroxidase-1 and the anabolism of collagen regulation pathway transforming growth factor-beta1-connective tissue growth factor in women with uterine prolapse and the clinic significance. Clin Exp Obstet Gynecol 40: 586-590, 2013.

34. Kim EJ, Chung N, Park SH, Lee KH, Kim SW, Kim JY, Bai SW and Jeon MJ: Involvement of oxidative stress and mitochondrial apoptosis in the pathogenesis of pelvic organ prolapse. J Urol 189: 588-594,2013.

35. Hong S, Li H, Wu D, Li B, Liu C, Guo W, Min J, Hu M, Zhao Y and Yang Q: Oxidative damage to human parametrial ligament fibroblasts induced by mechanical stress. Mol Med Rep 12: $5342-5348,2015$

36. Li BS, Guo WJ, Hong L, Liu YD, Liu C, Hong SS, Wu DB and Min J: Role of mechanical strain-activated PI3K/Akt signaling pathway in pelvic organ prolapse. Mol Med Rep 14: 243-253, 2016.

37. Fang G, Hong L, Liu C, Yang Q, Zhang Q, Li Y, Li B, Wu D, $\mathrm{Wu} \mathrm{W}$ and Shi H: Oxidative status of cardinal ligament in pelvic organ prolapse. Exp Ther Med 16: 3293-3302, 2018.

38. Stewart AG, Thomas B and Koff J: TGF- $\beta$ : Master regulator of inflammation and fibrosis. Respirology 23: 1096-1097, 2018.

39. Chen HY, Chung YW, Lin WY, Wang JC, Tsai FJ and Tsai CH: Collagen type 3 alpha 1 polymorphism and risk of pelvic organ prolapse. Int J Gynaecol Obstet 103: 55-58, 2008.

40. Jeon MJ, Chung SM, Choi JR, Jung HJ, Kim SK and Bai SW: The relationship between COL3A1 exon 31 polymorphism and pelvic organ prolapse. J Urol 181: 1213-1216, 2009.

41. Martins KF, de Jármy-DiBella ZI, da Fonseca AM, Castro RA, da Silva ID, Girão MJ and Sartori MG: Evaluation of demographic, clinical characteristics, and genetic polymorphism as risk factors for pelvic organ prolapse in Brazilian women. Neurourol Urodyn 30: 1325-1328, 2011.

42. Ricard-Blum S: The collagen family. Cold Spring Harb Perspect Biol 3: a004978, 2011

43. Lince SL, van Kempen LC, Dijkstra JR, IntHout J, Vierhout ME and Kluivers KB: Collagen type III alpha 1 polymorphism (rs1800255, COL3A1 $2209 \mathrm{G}>\mathrm{A}$ ) assessed with high-resolution melting analysis is not associated with pelvic organ prolapse in the Dutch population. Int Urogynecol J Pelvic Floor Dysfunct 25: $1237-1242,2014$

44. Teixeira FH, Fernandes CE, do Souto RP and de Oliveira E: Polymorphism rs1800255 from COL3A1 gene and the risk for pelvic organ prolapse. Int Urogynecol J Pelvic Floor Dysfunct 31 73-78, 2020.

45. Ward RM, Velez Edwards DR, Edwards T, Giri A, Jerome RN and Wu JM: Genetic epidemiology of pelvic organ prolapse: A systematic review. Am J Obstet Gynecol 211: 326-335, 2014.

46. Cartwright R, Kirby AC, Tikkinen KA, Mangera A, Thiagamoorthy G, Rajan P,Pesonen J,Ambrose C, Gonzalez-Maffe J, Bennett $\mathrm{P}$, et al: Systematic review and metaanalysis of genetic association studies of urinary symptoms and prolapse in women. Am J Obstet Gynecol 212: 199 e191-124, 2015.

47. Moon YJ, Bai SW, Jung CY and Kim CH: Estrogen-related genome-based expression profiling study of uterosacral ligaments in women with pelvic organ prolapse. Int Urogynecol J Pelvic Floor Dysfunct 24: 1961-1967, 2013.

48. Nakad B, Fares F, Azzam N, Feiner B, Zilberlicht A and Abramov Y: Estrogen receptor and laminin genetic polymorphism among women with pelvic organ prolapse. Taiwan J Obstet Gynecol 56: 750-754, 2017.

49. Dökmeci F, Teksen F, Cetinkaya SE, Özkan T, Kaplan F and Köse K: Expressions of homeobox, collagen and estrogen genes in women with uterine prolapse. Eur J Obstet Gynecol Reprod Biol 233: 26-29, 2019.

50. Shi Z, Zhang T, Zhang L, Zhao J, Gong J and Zhao C: Increased microRNA-221/222 and decreased estrogen receptor $\alpha$ in the cervical portion of the uterosacral ligaments from women with pelvic organ prolapse. Int Urogynecol J Pelvic Floor Dysfunct 23 929-934, 2012.

51. Ferrari MM, Rossi G, Biondi ML, Viganò $P$, Dell'utri $C$ and Meschia M: Type I collagen and matrix metalloproteinase 1, 3 and 9 gene polymorphisms in the predisposition to pelvic organ prolapse. Arch Gynecol Obstet 285: 1581-1586, 2012.
52. Wu JM, Visco AG, Grass EA, Craig DM, Fulton RG, Haynes C, Amundsen CL and Shah SH: Comprehensive analysis of LAMC1 genetic variants in advanced pelvic organ prolapse. Am J Obstet Gynecol 206: 447.e1-6, 2012.

53. Chen HY, Chung YW, Lin WY, Chen WC, Tsai FJ and Tsai CH: Progesterone receptor polymorphism is associated with pelvic organ prolapse risk. Acta Obstet Gynecol Scand 88: 835-838, 2009.

54. Khadzhieva MB, Kamoeva SV, Ivanova AV, Abilev SK and Salnikova LE: Elastogenesis-Related Gene Polymorphisms and the Risk of Pelvic Organ Prolapse Development. Genetika 51: 1191-1198, 2015 (In Russian).

55. Khadzhieva MB, Kamoeva SV, Chumachenko AG, Ivanova AV, Volodin IV, Vladimirov IS, Abilev SK and Salnikova LE: Fibulin-5 (FBLN5) gene polymorphism is associated with pelvic organ prolapse. Maturitas 78: 287-292, 2014.

56. Paula MVB, Lira Junior MAF, Monteiro VCESC, Souto RP, Fernandes CE and Oliveira E: Evaluation of the fibulin 5 gene polymorphism as a factor related to the occurrence of pelvic organ prolapse. Rev Assoc Med Bras 66: 680-686, 2020.

57. Allen-Brady K, Norton PA, Farnham JM, Teerlink C and Cannon-Albright LA: Significant linkage evidence for a predisposition gene for pelvic floor disorders on chromosome $9 \mathrm{q} 21$. Am J Hum Genet 84: 678-682, 2009.

58. Allen-Brady K, Cannon-Albright LA, Farnham JM and Norton PA: Evidence for pelvic organ prolapse predisposition genes on chromosomes 10 and 17. Am J Obstet Gynecol 212: 771 e771-777, 2015.

59. Khadzhieva MB, Kolobkov DS, Kamoeva SV, Ivanova AV, Abilev SK and Salnikova LE: Verification of the Chromosome Region 9q21 Association with Pelvic Organ Prolapse Using RegulomeDB Annotations. BioMed Res Int 2015: 837904, 2015.

60. Zhou Q, Hong L and Wang J: Identification of key genes and pathways in pelvic organ prolapse based on gene expression profiling by bioinformatics analysis. Arch Gynecol Obstet 297: 1323-1332, 2018

61. McDermaid A, Monier B, Zhao J, Liu B and Ma Q: Interpretation of differential gene expression results of RNA-seq data: Review and integration. Brief Bioinform 20: 2044-2054, 2019.

62. van Dijk EL, Jaszczyszyn Y, Naquin D and Thermes C: The Third Revolution in Sequencing Technology. Trends Genet 34: 666-681, 2018

63. Hu JM, Wang L, Cheng X, Zhou LH and Li ZG: Neuropeptide Y innervation in the vaginal mucosa among patients with pelvic organ prolapse. Mol Med Rep 5: 444-448, 2012.

64. Hu JM, Cheng X, Wang L, Zhu JN and Zhou LH: Vasoactive intestinal peptide expression in the vaginal anterior wall of patients with pelvic organ prolapse. Taiwan J Obstet Gynecol 52: 233-240, 2013.

65. Rahn DD, Ward RM, Sanses TV, Carberry C, Mamik MM, Meriwether KV, Olivera CK, Abed H, Balk EM and Murphy M; Society of Gynecologic Surgeons Systematic Review Group: Vaginal estrogen use in postmenopausal women with pelvic floor disorders: Systematic review and practice guidelines. Int Urogynecol J Pelvic Floor Dysfunct 26: 3-13, 2015.

66. Edwall L, Carlström K and Jonasson AF: Endocrine status and markers of collagen synthesis and degradation in serum and urogenital tissue from women with and without stress urinary incontinence. Neurourol Urodyn 26: 410-415, 2007.

67. Tomaszewski J, Adamiak-Godlewska A, Bogusiewicz M, Brzana W, Juszczak M, Rzeski W and Rechberger T: Collagen type III biosynthesis by cultured pubocervical fascia fibroblasts surrounding mono and multifilament polypropylene mesh after estrogens and tamoxifen treatment. Ginekol Pol 81: 493-500, 2010 (In Polish).

68. Tanaka T, Saito Y, Matsuda K, Kamio K, Abe S, Kubota K, Azuma A and Gemma A: Cyclic mechanical stretch-induced oxidative stress occurs via a NOX-dependent mechanism in type II alveolar epithelial cells. Respir Physiol Neurobiol 242: 108-116, 2017.

69. Rahn DD, Carberry C, Sanses TV, Mamik MM, Ward RM, Meriwether KV, Olivera CK, Abed H, Balk EM and Murphy M; Society of Gynecologic Surgeons Systematic Review Group: Vaginal estrogen for genitourinary syndrome of menopause: A systematic review. Obstet Gynecol 124: 1147-1156, 2014.

70. Wasenda EJ, Kamisan Atan I, Subramaniam N and Dietz HP: Pelvic organ prolapse: Does hormone therapy use matter? Menopause 24: 1185-1189, 2017.

This work is licensed under a Creative Commons Attribution-NonCommercial-NoDerivatives 4.0 International (CC BY-NC-ND 4.0) License. 